\title{
Missing or Inadequate Safety Measures Problem
}

National Cancer Institute

\section{Source}

National Cancer Institute. Missing or Inadequate Safety Measures Problem. NCI

Thesaurus. Code C139481.

Problems traced to inadequate design or complete lack of safety measures leading to device malfunction or unintended properties of the device including possible hazards for persons using the device. 